\title{
The Application of Laser Microdissection to In Planta Gene Expression Profiling of the Maize Anthracnose Stalk Rot Fungus Colletotrichum graminicola
}

\author{
Weihua Tang, ${ }^{1}$ Sean Coughlan, ${ }^{2}$ Edmund Crane, ${ }^{1}$ Mary Beatty, ${ }^{1}$ and Jon Duvick ${ }^{1}$ \\ ${ }^{1}$ Pioneer Hi-Bred International, A DuPont Company, Johnston IA 50131-1004 U.S.A.; ${ }^{2}$ Agilent Technologies, Wilmington, \\ DE 19808 U.S.A.
}

Submitted 30 April 2006. Accepted 26 June 2006.

Laser microdissection (LM) offers a potential means for deep sampling of a fungal plant-pathogen transcriptome during the infection process using whole-genome DNA microarrays. The use of a fluorescent protein-expressing fungus can greatly facilitate the identification of fungal structures for LM sampling. However, fixation methods that preserve both tissue histology and protein fluorescence, and that also yield RNA of suitable quality for microarray applications, have not been reported. We developed a microwave-accelerated acetone fixation, paraffin-embedding method that fulfills these requirements and used it to prepare mature maize stalk tissues infected with an Anemonia majano cyan fluorescent protein-expressing isolate of the anthracnose stalk rot fungus Colletotrichum graminicola. We successfully used LM to isolate individual maize cells associated with $C$. graminicola hyphae at an early stage of infection. The LM-derived RNA, after two-round linear amplification, was of sufficient quality and quantity for global expression profiling using a fungal microarray. Comparing replicated $L M$ samples representing an early stage of stalk cell infection with samples from in vitro-germinated conidia, we identified 437 and $370 C$. graminicola genes showing significant up- or downregulation, respectively. We confirmed the differential expression of several representative transcripts by quantitative reverse-transcriptase polymerase chain reaction (RT-PCR) and documented extensive overlap of this dataset with a PCR-subtraction library enriched for $C$. graminicola transcripts in planta. Our results demonstrate that $\mathrm{LM}$ is feasible for in planta pathogen expression profiling and can reveal clues about fungal genes involved in pathogenesis. The method in this report may be advantageous for visualizing a variety of cellular

Corresponding author: J. Duvick; E-mail: jon.duvick@mchsi.com

Current address of W. Tang: Institute of Plant Physiology and Ecology, Shanghai Institute for Biological Sciences, The Chinese Academy of Sciences, 300 Fenglin Road, Shanghai 200032, China.

The genomic DNA sequences for CgBOup1, CgBOup2, CgBOup6, CgBOdown1, CgBOdown2, CgBOdown198, and the EF-2-like gene are available in the GenBank database under accession numbers DQ512319, DQ512320, DQ512321, DQ512322, DQ512323, DQ512325, and DQ512324, respectively.

* The $\boldsymbol{e}$-Xtra logo stands for "electronic extra" and indicates the HTML abstract available on-line contains supplemental material not included in the print edition. One supplemental table and five supplemental figures appear online. features that depend on a high degree of histochemical preservation and RNA integrity prior to $L M$.

Additional keywords: oligonucleotide microarray, phytase.

One of the goals of fungal plant pathology research has been to identify the fungal genes and pathways involved in the process of infection and colonization of plant tissues. Now that entire fungal pathogen genomes and their predicted transcriptomes are becoming available (Dean et al. 2005; Güldener et al. 2006a), new tools based on global measurement of gene expression can be applied to this goal. One such tool involves global RNA transcript profiling at discrete developmental stages, which can provide useful information about gene function and allow putative assignment of genes to functional pathways (Wu et al. 2002). The ability to delineate fungal gene expression at discrete stages of infection and colonization of the plant host would be extremely valuable. However, for most pathogens, it usually is difficult to physically separate fungal hyphae from a large excess of host tissue, resulting in a less than ideal signal-to-noise ratio. In addition, it is difficult to capture a developmentally discrete stage of infection using macroscopic harvesting methods. Subtractive hybridization can improve signal-to-noise by providing gene sets enriched in pathogen-derived cDNAs (Sugui and Deising 2002) but gives only rough quantitative information and is not designed to generate a global, staged transcription pattern. Fungal transcript patterns in nitrogen-starved or minimal media (Pellier et al. 2003) can approximate, but not necessarily duplicate, in planta conditions.

Laser microdissection (LM) is a powerful tool for the isolation of discrete cell populations and their contents from heterogeneous tissues for subsequent molecular analysis (Cornea and Mungenast 2002; Nelson et al. 2006). In brief, the tissues first are fixed and sectioned, and then the target cells are isolated from nontarget cells under a microscope using a laser microbeam. RNA recovered from collected target cells can be used for global analysis of gene expression, following suitable amplification. Thus, LM provides a way to maximize signal-to-noise ratio for in planta fungal gene expression profiling, and could facilitate developmentally staged, deep profiling of fungal genes during infection. LM combined with microarray analysis has been applied successfully to gene profiling of specific plant cell types (Casson et al. 2005; Nakazono et al. 2003; Woll et al. 2005), and LM followed by reverse-transcriptase-polymerase 
chain reaction (RT-PCR) analysis and cDNA library construction has been used to study plant-nematode interactions (Klink et al. 2005; Ramsay et al. 2004). However, the cryosectioning method used in some of these reports can result in ice crystals in vacuoles and air spaces between cells in mature plant tissues that compromise histological features. Therefore, application of this method in plant has been limited to either small, cytoplasmically dense embryonic cells or cells having very distinguishable morphological characteristics, such as vascular tissues or epidermal layers (Asano et al. 2002; Casson et al. 2005; Nakazono et al. 2003; Woll et al. 2005). On the other hand, paraffin embedding and sectioning have been applied successfully to various plant tissues for LM (Inada and Wildermuth 2005; Jiang et al. 2006; Kerk et al. 2003; Ramsay et al. 2004), but no microarray studies have yet been published with these methods, which are expected to be less conducive to RNA preservation. For LM studies involving fungal infection of plant tissues, a method that combines the histological detail possible with chemical fixation with the high RNA integrity of cryofixation is highly desirable.

We set out to develop LM techniques that would allow us to identify the genes and pathways involved in early infection of maize stalk tissues by Colletotrichum graminicola as a first step toward designing novel control strategies. C. graminicola (Ces.) G. W. Wils. is a filamentous ascomycete that is the causal agent of maize anthracnose stalk rot and leaf blight. Anthracnose stalk rot is an economically important maize disease causing plants to lodge (Bergstrom and Nicholson 1999). In leaf infection, $C$. graminicola is a hemibiotroph that colonizes the host initially without damaging cells and, later, switches to necrotrophic growth where large areas of plant tissue are destroyed (Latunde-Dada 2001). How stalk infection occurs in nature is not clear, and little is known about the course of infection of stalk tissue even though this is a critical tissue in terms of economic impact of the disease.

Here, we report a microwave-accelerated, acetone fixation/ paraffin embedding method that preserves both RNA quality and section histology, as well as retaining Anemonia majano cyan (AmCyan) protein fluorescent activity to facilitate local- ization of fungal hyphae in planta. With this novel method, we successfully used LM to isolate individual maize stalk cells associated with $C$. graminicola hyphae at an early stage of infection. With two-round linear amplification, the LM-derived RNA was of sufficient quality and quantity for subsequent microarray analysis using an Agilent 60-mer fungal microarray. Using this method, we were able to identify and validate a number of fungal transcripts associated with early infection of stalk parenchyma.

\section{RESULTS}

\section{"Breakout" zones represent an early infection stage of Colletotrichum spp. in maize stalk.}

The pattern of $C$. graminicola colonization inside a mature maize stalk has not been well documented to date. To determine the tissue to be sampled, we wounded maize stalk internodes and inoculated wound sites with a transgenic C. graminicola strain that constitutively expresses the reef coral fluorescent protein AmCyan under the control of a strong constitutive promoter (Fig. 1A). We observed fungal growth in the stalk from 1 to 7 days post inoculation (dpi) and were able to reconstruct a growth pattern that is summarized in Figure 1B.

At 1 dpi, the $C$. graminicola spores had germinated and fungal hyphae had invaded the parenchyma cells around the wounding site up to several cell layers away. Meanwhile, some hyphae had migrated up to several centimeters away from the wounding site, apparently progressing within vascular bundles. From these distal infection zones, a few hyphae could be observed emerging from the vascular bundles and invading the neighboring parenchyma cells to form a small "breakout" zone that is isolated from the wounding site (Fig. 1C). At 2 dpi, many more breakout zones were observed, expanding in diameter as hyphae extended further and invaded more host parenchyma cells. By 4 dpi, the fungal hyphae had extended to most areas in the wounded internode. The more mature breakouts appeared to have completely destroyed the maize tissue in the area and the hyphae appeared to be senescing. Occasionally, acervuli (sporulation structures) with maturing falcate spores
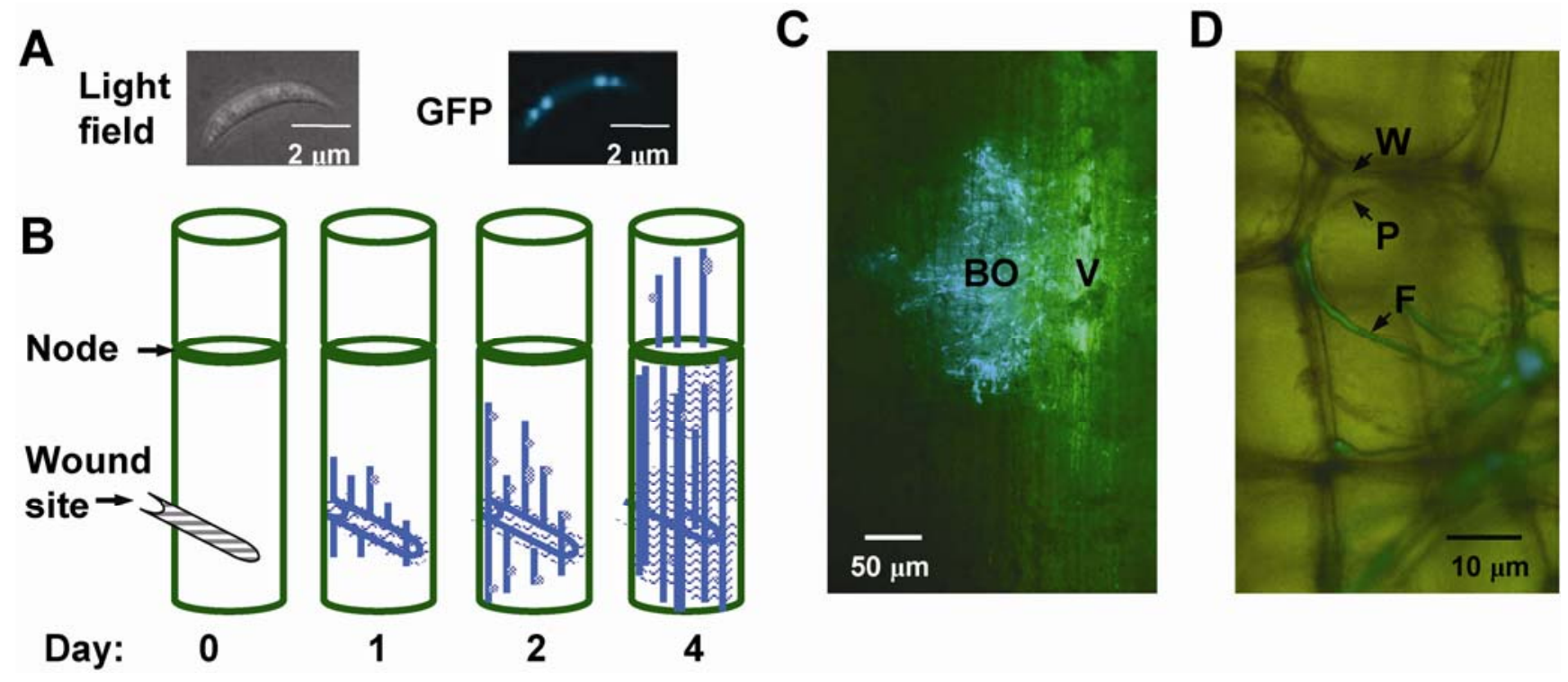

Fig. 1. Colletotrichum graminicola (AmCyan) growth pattern in the maize stalk. A, Microscopic pictures of a representative spore of $C$. graminicola (AmCyan) used in inoculation, shown under light field (left) and green fluorescent protein (GFP) longpass filter (right). B, Diagram of the growth pattern in maize, with time indicated as the number of days after inoculation. C, Photomicrograph under GFP longpass filter showing a representative "breakout" zone (BO) originating from vascular tissue (V). D, Photomicrograph showing the plasmolysis of a representative maize parenchyma cell (center) in direct contact with fungal hyphae $(\mathrm{F})$ after $10 \mathrm{~min}$ of salt treatment. The picture is an overlay of light-field and UV-excited fluorescence. P: plasma membrane of the parenchyma cell; W: cell wall of the parenchyma cell. 
could be observed in the mature breakout area. At this time, in the internode adjacent to the wounded one, fungal fluorescent signal could be observed inside some vascular bundles as well as in a few new breakouts. By $7 \mathrm{dpi}$, the wounded internode had been completely rotted, and breakouts in the neighboring internode became more frequent and larger. In multiple experiments, we found this sequence of events: linear fungal growth associated with vascular bundles, hyphal breakout from vascular bundles into parenchyma tissue, and breakouts expanding to occupy the whole internode, although the exact timing of the events varied depending on the amount and viability of inoculated spore suspension and the position of the wounded internode.

According to our observations, the breakout may represent an early stage of stalk pith infection. To determine whether it represents a biotrophic or necrotrophic phase of infection, we made live sections of the wounded internode at 2 dpi and challenged the infected tissue with hyperosmotic sodium chloride. In most cases, we could find some host parenchyma cells interacting with fungal hyphae and showing plasmolysis (Fig. 1D), which indicates an intact plasma membrane (Lee-Stadelmann and Stadelmann 1989). Therefore, we chose to use the breakout zone to represent the pre- or early necrotrophic stage of in planta fungal growth for expression profiling.

\section{Optimization of tissue preparation method for LM.}

Ethanol-acetic acid fixation followed by cryosectioning has been used successfully for LM-mediated harvest and subsequent microarray analysis of epidermal cells, vascular tissues, and embryo tissues (Casson et al. 2005; Nakazono et al. 2003), as well as young root tissues (Woll et al. 2005). However, this method was inadequate to allow us to identify individual $\mathrm{Col}$ letotrichum-invaded parenchyma cells of maize stalk, and it also destroyed AmCyan fluorescent protein activity (data not shown).

Paraffin sectioning combined with various fixatives has been reported to provide superior preservation of plant tissue mor-
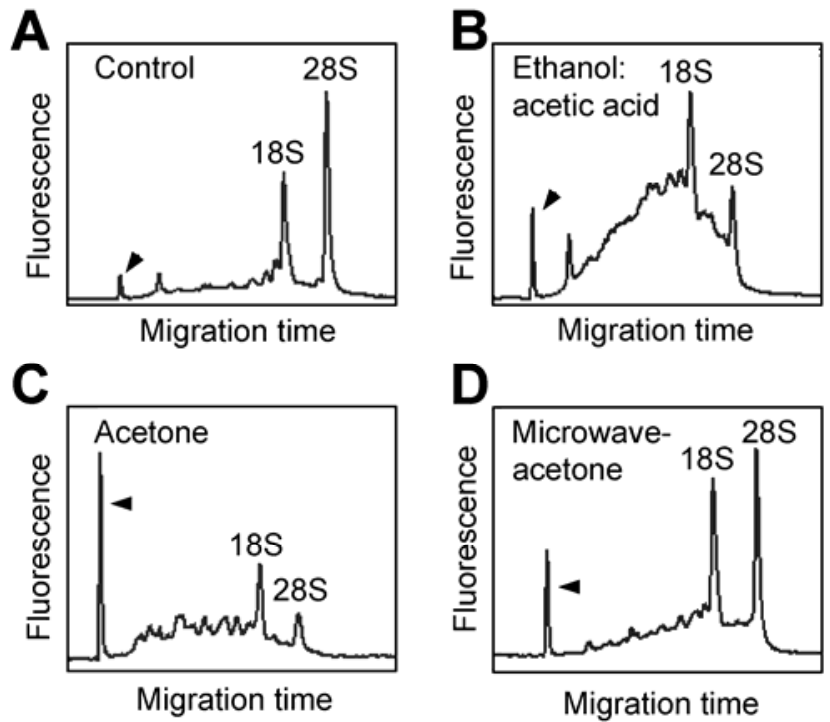

Fig. 2. Effect on RNA integrity of different fixation methods followed by paraffin-embedding and sectioning as measured using an Agilent 2100 Bioanalyzer. The infected maize stalk tissues were prepared by $\mathbf{A}$, the fresh frozen method and three different chemical fixation methods: B, ethanol:acetic acid, $\mathbf{C}$, acetone, and $\mathbf{D}$, microwave-accelerated acetone. On each representative electropherogram image, the $18 \mathrm{~S}$ and $28 \mathrm{~S}$ ribosomal RNA peaks are indicated, and the first peak (as shown by an arrow) from the left is a 50-bp marker added to all samples. phology compared with freezing-cryosectioning; however, improvement was needed in preserving RNA quality. The quality of RNA in a tissue sample is determined mainly by the fixation procedure (Benchekroun et al. 2004); therefore, we sought to optimize the sample preparation method for LM by testing and combining reported fixatives and evaluating the effect on subsequent RNA quality.

Both ethanol-acetic acid (Kerk et al. 2003) and acetone (K. Ohtsu and P. Schnable, Iowa State University, personal communication) have been used in combination with paraffin-embedding and sectioning for LM of plant cells, and microwave irradiation has been reported to improve RNA preservation in LM of mature Arabidopsis leaf cells (Inada and Wildermuth 2005). Therefore, we compared three methods for preparing infected mature maize stalk pith tissues: the ethanol/acetic acid method as reported (Kerk et al. 2003), the acetone method according to the Ohtsu and Schnable protocol, and a new method combining microwaving with acetone fixation. The subsequent RNA integrity was assessed by capillary electrophoresis on an Agilent 2100 Bioanalyzer. The microwave-accelerated acetonefixation method (Fig. 2D) yielded RNA much closer in quality to control RNA (Fig. 2A) than did either ethanol/acetic acid (Fig. 2B) or acetone (Fig. 2C), as judged by relative peak heights for $18 \mathrm{~S}$ and $28 \mathrm{~S}$ ribosomal RNAs. We also determined that the new method recovered significantly more total RNA than the acetone method, although RNA yield was less than the ethanol/acetic acid method.

We also examined the performance of the new method in preserving tissue morphology. Individual cells in a maize stalk tissue could be recognized easily (Fig. 3A). Significantly, the sample prepared by the new method also preserved AmCyan fluorescent activity. The hyphae could be recognized by AmCyan fluorescence, even though background autofluorescence from host cell walls was present (Fig. 3B). This feature allowed us to distinguish infected maize cells that contain fungal hyphae from the surrounding, uninfected maize cells.

\section{LM of individual maize cells associated with Colletotrichum hyphae.}

We used the new method to prepare sections of C. graminicola-infected maize stalk tissues which then were employed for LM using a PALM laser microbeam system. The maize cells containing fungal hyphae in the early breakout zones were visualized and individually isolated (Fig. 4). In total, two independent samples, each consisting of approximately 800 cells (called "LM-BO" hereafter) were collected to represent in planta fungal growth. For mock-inoculated controls, we also collected two samples of uninfected parenchyma cells, each containing approximately 800 maize cells from a mock-inoculated stalk.
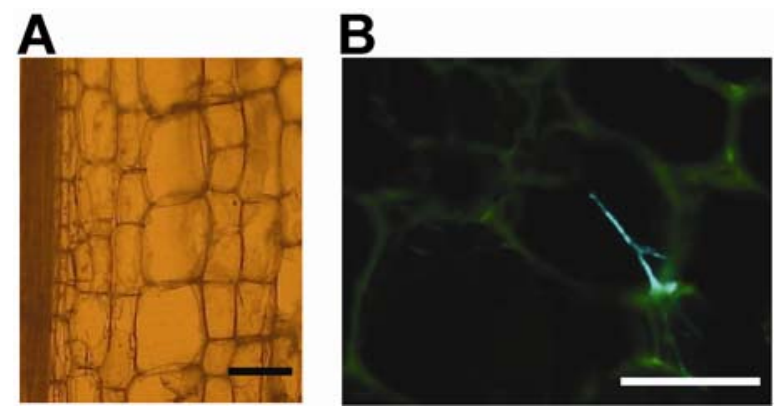

Fig. 3. Maize stalk longitudinal sections prepared by microwave-accelerated acetone-fixation paraffin-embedding method, showing preservation of tissue morphology under A, bright-field illumination and $\mathbf{B}$, AmCyan fluorescent activity viewed with green fluorescent protein filter. The scale bar is $20 \mu \mathrm{m}$. 
We obtained 2 to $3 \mathrm{ng}$ of total RNA from each LM-BO sample and 1 to $1.5 \mathrm{ng}$ of total RNA from each mock sample. The RNA quality of LM-derived samples was comparable to that of the samples before LM (Fig. 5A).

\section{Linear amplification of LM-derived RNA.}

A typical microarray experiment requires several micrograms of antisense messenger (m)RNA for hybridization, whereas an LM sample provides only a few nanograms of total RNA per 800 to 1,000 cells, yielding 10 to $20 \mathrm{pg}$ of mRNA. A T7-based linear amplification procedure often is used to amplify RNA for microarray use because the T7 RNA polymerase procession rate is relatively unaffected by template sequence or by template concentration in a complex mixture. However, the maximum amplification achievable is approximately 1,000-fold, which is not sufficient for LM RNA amounts. Two-round (Nakazono et al. 2003; Woll et al. 2005) or three-round (Casson et al. 2005) linear amplification have been used for microarray analysis of laser microdissected plant tissues; however, the fidelity of multiple-round amplification has not been addressed experimentally.

For our experiments, we used an Epicentre two-round antisense (a)RNA amplification kit to amplify approximately $1 \mathrm{ng}$ of total RNA from LM. Typical yields were approximately 10 $\mu \mathrm{g}$ of antisense RNA, representing 1,000,000-fold amplification. The size of the amplified aRNA ranged from 0.1 to $2 \mathrm{~kb}$, with a peak at approximately $0.3 \mathrm{~kb}$ (Fig. 5B). We also used two-round amplification for the in vitro-cultured $C$. graminicola ( $C g r$-in vitro) sample in order to minimize variables involved in the array comparisons with laser-captured material.

In addition, we tested the fidelity of two-round amplification compared with one-round amplification by microarray analysis on a customized Agilent oligonucleotide microarray containing 16,000 C. graminicola features (see below). These arrays measure relative hybridization between two fluorescently labeled cRNA samples, and replicate samples are used to determine significance of hybridization ratios different from 1.0 for each array feature. For fidelity experiments, we extracted RNA from $C g r$-in vitro and hand-dissected C. graminicola-infected
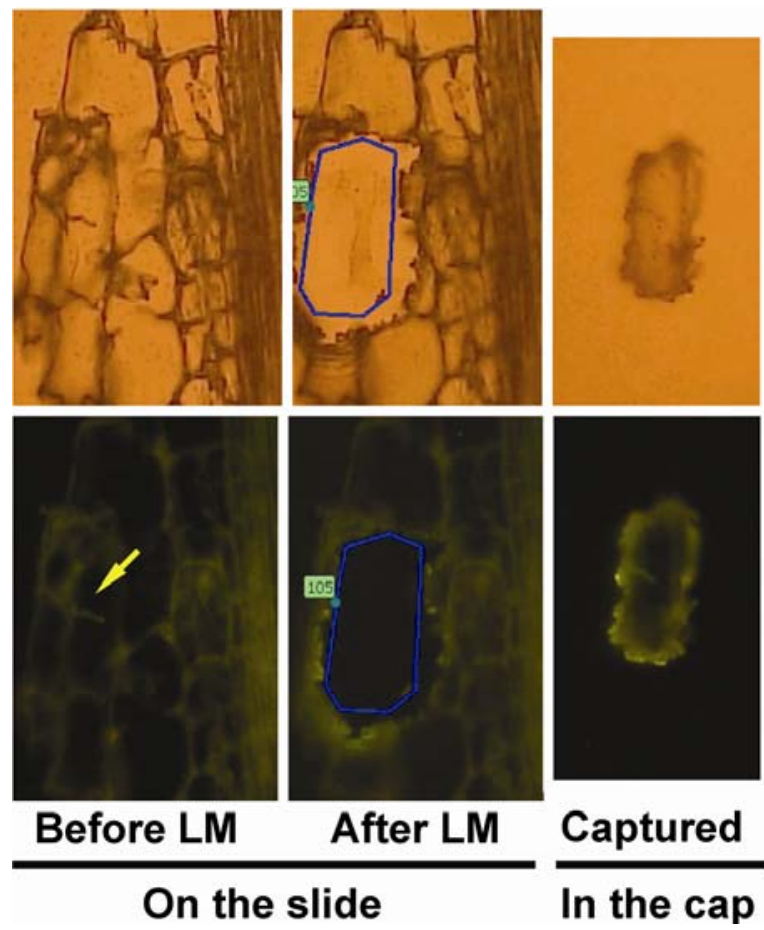

Fig. 4. Selection of individual cells invaded by Colletotrichum graminicola hyphae using laser microdissection. maize stalk pith tissues harvested 5 days after inoculation (Cgr-infected). Replicate RNA samples were subjected to either one-round or two-round amplification, labeled, and hybridized to a series of microarray slides to compare gene expression in vitro and in planta. The correlation coefficient between the comparison based on one-round amplified RNA and that based on two-round amplified RNA was 0.78 , an acceptable number though less than ideal. Among all 16,000 C. graminicola features, approximately 11,600 signatures were correlated, and only 439 were anti-correlated.

\section{Microarray analysis}

of Colletotrichum gene expression changes

between in vitro and in planta growth.

The Agilent microarray employed in this study contains a total of 44,000 features, of which approximately 16,000 were designed to represent predicted transcripts of $C$. graminicola, based on a proprietary partial genome sequence of $C$. graminicola. Each feature consists of one 60-mer oligonucleotide, designed to represent a specific transcribed portion of a gene. The genes covered on this chip are estimated to represent more than half of the $C$. graminicola genome.

Our objective was to investigate differences in gene expression between in vitro growth and early growth in living stalk tissues (referred to as in planta growth) in order to gain insight into the genes and pathways specifically associated with growth in planta. We used two-round amplified RNA from LM-BO samples to represent in planta growth. To represent in vitro growth, we used two-round amplified RNA from in vitrogerminated spores and resulting hyphae that were processed by the same fixation, embedding, and sectioning procedure but without LM. We hybridized eight chips in total, comprising two biological replicates.

Because the aRNA probes we used were extracted from lasermicrodissected samples and two-round amplified, we first wanted to address the quality of our microarray data. We evaluated quality based on the following aspects. First, the correlation coefficients between technical replicates were approximately 0.99 for all signatures at the level of $P<0.001$ (Fig. 6A), an indication that array-to-array reproducibility was high. As expected, the results from the dyeswaps were mostly anti-correlated (Fig. 6B). Second, we evaluated the reproducibility between biological replicates. The correlation coefficient between the two biological replicates (each of which comprises four arrays) was approximately 0.70 for all the signatures at the level of $P<0.0001$ (Fig. 6C). For the present study, we took only correlated data points into account when we analyzed up- and downregulated genes (Fig. 7).

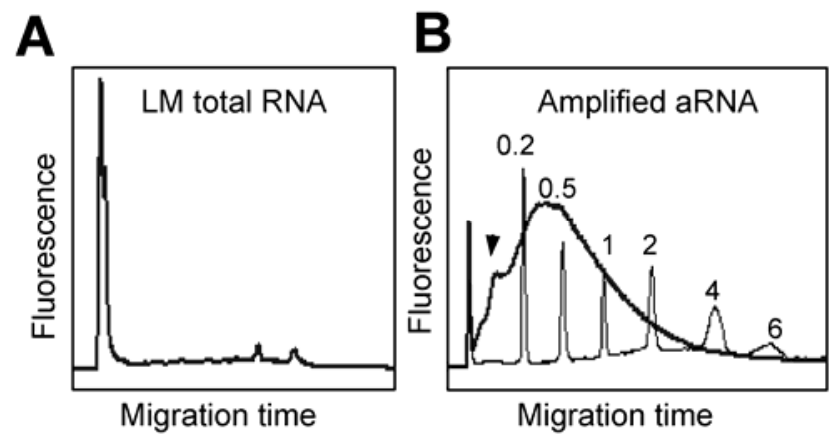

Fig. 5. Electropherograms of total RNA of a representative laser microdissection (LM) sample. A, Total RNA from LM sample. B, Antisense RNA resulting from a two-round amplification. The blue curve represents the RNA ladder run on the same chip; the size of ladder is indicated above the corresponding peaks (unit:kb). The arrow points to a discrete peak identified as representing nonspecific amplification products. 
In order to estimate cross-hybridization noise, we compared the LM-derived $C g r$-in planta sample (i.e., LM-BO) to the mock sample on two fungal microarrays. We hybridized the same amount of aRNA for LM-BO and LM-mock on each array, and expected to see almost no signal from the mock sample. Results showed that the mean ratio of the total raw intensity of mock sample versus LM-BO sample was 0.148 . This indicates that the nonspecific hybridization caused by the nonrelevant plant RNA contributes less than $15 \%$ of the signal overall. Of 16,000 features, 8,505 (53.2\%) showed at least twofold greater intensity in the LM-BO channel than in the mock channel, as well as at least 500 intensity units in the LMBO channel, designated as detectable genes. In another example, Güldener and associates (2006b) reported that approximately $70 \%(10,000$ of 14,000) of all the Fusarium graminearum
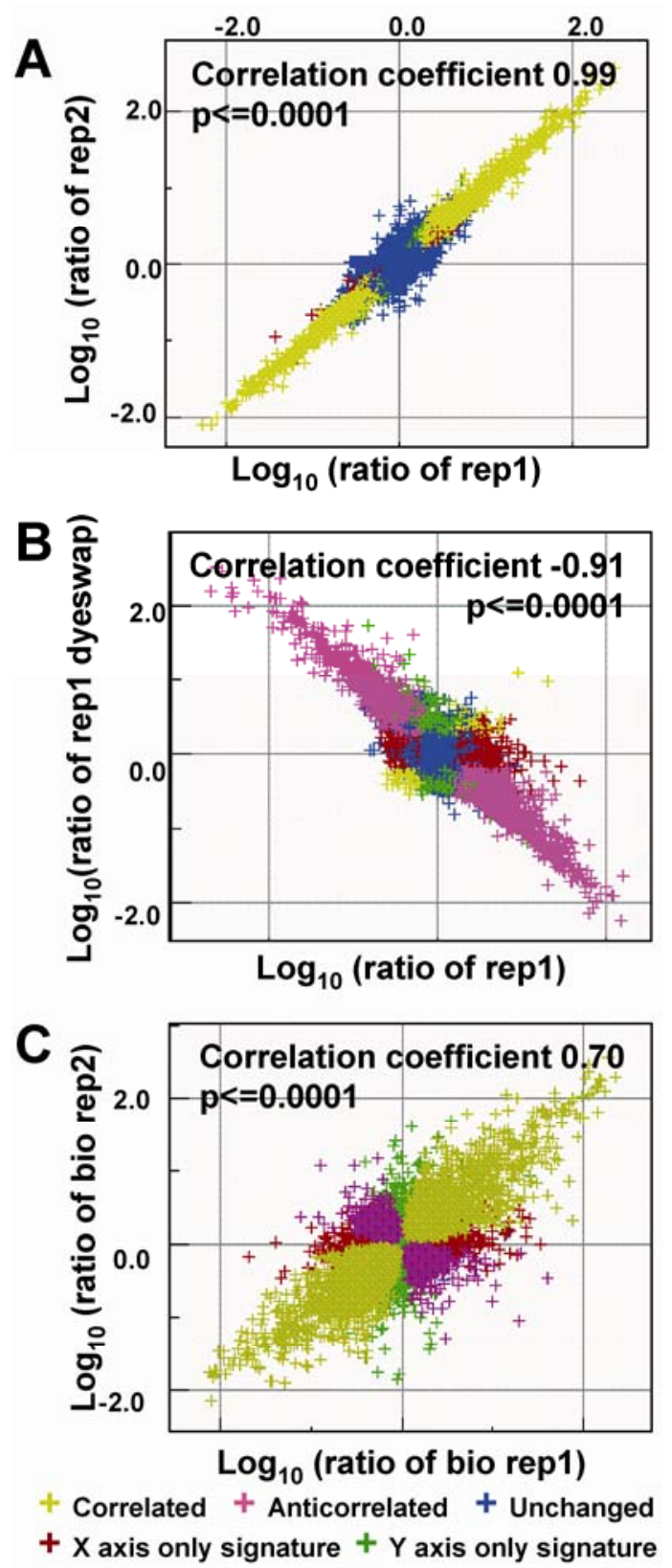

Fig. 6. Evaluation of microarray quality using two-round amplified cRNA. A, Representative correlation plot comparing the results from two technical replicates (slide 2 and 4). B, Representative correlation plot of the results between dye-swapped replicates (slides 1 and 2). C, Correlation plot of the results between two biological samples, each combining four array results (two dye swaps and two technical reps). genes on an Affymetrix GeneChip had detectable expression under in vitro culture. If we consider that $70 \%$ represents a rough percentage of genes with expression at a specific stage that is detectable above noise, we estimated that the use of laser-microdissected samples for in planta fungal expression profiling provided a signal-to-noise ratio adequate for sampling a similarly high portion of the fungal transcriptome.

In addition to background hybridization, there is a possibility that individual maize RNAs with high homology to one or more fungal 60 mers could contribute to false positives in our experiments if the same maize RNA also is significantly induced by fungal infection. Given the evolutionary divergence of maize and Colletotrichum spp. and the limited set of plant genes typically induced during infection, this class of false positives is likely to be small in number.

Of the 8,505 features classified as detectable in planta, 437 showed at least a twofold increase in in planta expression and another 370 showed at least twofold downregulation, whereas 3,174 showed no significant change. We used twofold as a threshold for meaningful difference because, when we performed a self-comparison on the microarray, more than $99.5 \%$ of $C$. graminicola features showed less than a twofold difference in expression.

We confirmed the in planta and in vitro expression of several previously characterized $C$. graminicola genes encoding putative housekeeping proteins, including TUB2 ( $\beta$-tubulin) (Panaccione and Hanau 1990) and CPR1 (Thon et al. 2002) (data not shown). Several infection-specific sequence tags of fungal origin from $C$. graminicola-infected maize leaves were reported recently (Sugui and Deising 2002) but, unfortunately, these sequences were not included among our microarray features.

Among the $C$. graminicola genes we classified as upregulated in planta, the respective encoded protein products included putative oxidoreductases, transporters, hydrolases (including phosphatases), proteases, and transcription factors. Not surprisingly, different members of similar protein categories also were found on the unchanged or downregulated list.

The most dramatically upregulated genes, named CgBOup1 and $\mathrm{CgBOup} 2$, encode a hypothetical protein and a protein similar to phytase A (myo-inositol hexakisphosphate phosphohydrolase A, EC 3.1.3.8), respectively. Based on the microarray data, the expression level of $\mathrm{CgBOup} 1$ and $\mathrm{CgBOup} 2$ in the breakout stage of infection increased 146-fold and 109fold, respectively, compared with the in vitro growth stage. CgBOup2 had almost no expression in in vitro-germinated spores. Interestingly, a phytase B family homolog, CgBOup6, with sequence similarity to acid phosphatase PHO1 (P52291), was 59-fold upregulated in planta.

The most dramatically downregulated genes, CgBOdown 1 and CgBOdown2 (125-fold and 108-fold lower in planta than in vitro, respectively) encode a protein with low similarity to a putative extracellular lipase (EAL92198) and another protein with no significant homology to any known proteins, respectively.

Within the subset of differentially expressed genes, we uncovered an interesting trend related to the predicted subcellular localization of their protein products (Fig. 8). Among the 8,242 C. graminicola putative proteins for which we were able to make a prediction, $13.1 \%$ were predicted to be secreted; whereas, among the 267 in planta upregulated proteins for which localization could be predicted, $21.7 \%$ were predicted to be secreted. The proportion of secreted proteins among the downregulated group was $14.5 \%$, essentially unchanged from the overall proportion. The enrichment of putative extracellular proteins in planta was more significant in the most dramatically upregulated group. Among the 27 genes that were more 
than 20-fold upregulated, $15(55.6 \%)$ were predicted to encode extracellular proteins.

Validation of differential gene expression.

We used two methods to validate our microarray data. First, we constructed a PCR-based cDNA subtraction library using the laser microdissected sample of $C$. graminicola-invaded maize stalk parenchyma cells from the breakout zone as tester cDNA. Driver cDNA was obtained from a pool of the mockinoculated stalk tissue RNA and in vitro-cultured $C$. graminicola RNA. Thus, the resulting library was enriched for both fungal and plant genes preferentially expressed in the early stages of stalk infection. Ideally, the $C$. graminicola genes enriched in this subtraction library should include many of the genes with increased expression in the microarray comparison of LM-BO versus $C g r$-in vitro. The first 1,000 sequences that we analyzed from the subtraction library fell into 690 distinct sequences. Of these, 158 were sequenced at least twice, therefore representing the most enriched group. Although only 33 of these 158 genes were represented by one or more features on the Agilent fungal array, 25 of these $33(76 \%)$ fell into the morethan-twofold upregulated class in our microarray experiment.

Second, we performed quantitative RT-PCR with SYBR Green detection for five individual genes to test their relative expression level. We designed specific primers to target Colletotrichum genes that do not result in any amplification products from a mock-inoculated maize RNA sample. Therefore, we could reasonably use the RNA extracted from a hand-dissected sample of Colletotrichum-infected maize stalk tissue containing the breakout zones as templates for in planta expression detection, compared with in vitro expression, although these samples also would contain RNA from infection stages not sampled by LM (such as vascular bundle-associated growth). The RNA extracted from mock-inoculated maize stalk was used as a negative control. The AmCyan gene, driven by the constitutive MgRP27 promoter, was used as a reference gene for quantitative PCR. We calculated that CgBOup2 and CgBOup6 expression increased 131- and 96-fold, respectively,
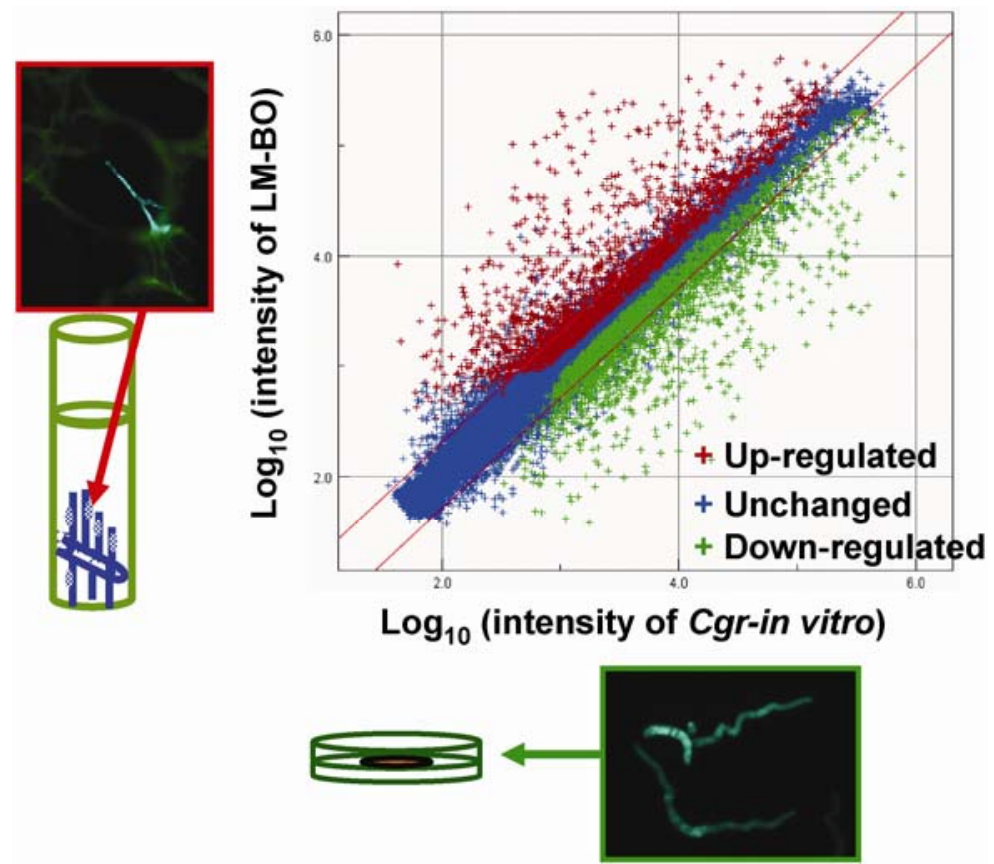

Fig. 7. Intensity plot of the microarray comparison between laser microdissection breakout (LM-BO) and Colletotrichum graminicola (Cgr)-in vitro (two biological samples combined and eight slides total). $P$ value was set at 0.001 .

All

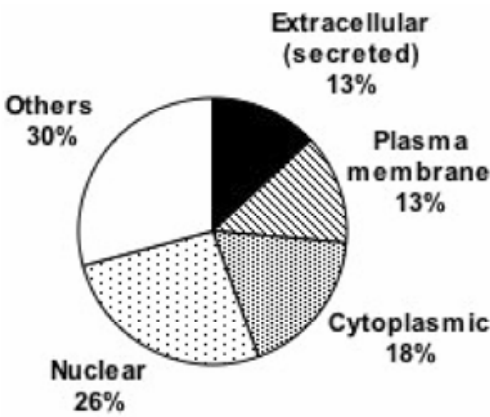

Up

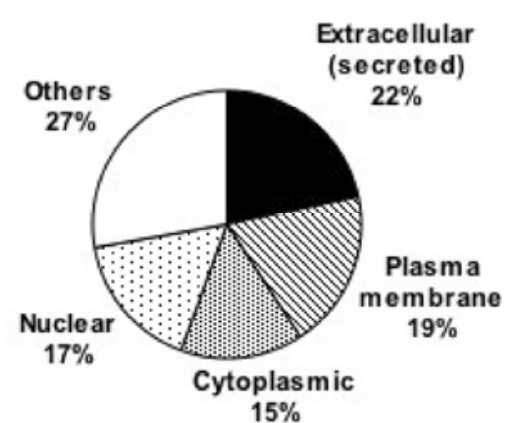

Down

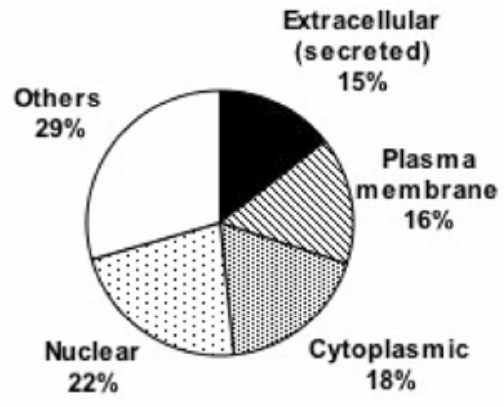

Fig. 8. Summary of the subcellular localization prediction of putative proteins encoded by all-, up-, and downregulated Colletotrichum graminicola genes. Included in the prediction were 8,242 of the 16,000 features on the array, which encompassed 267 of 437 upregulated features and 243 of 370 downregulated features. 
in planta compared with in vitro, which is consistent with the microarray data showing a 109- and 59-fold increase, respectively. Quantitative PCR also revealed that the CgrTUB2 gene had slightly reduced (1.83-fold) expression in planta, whereas the microarray data showed 1.14-fold reduction. Another putative constitutive gene, the Colletotrichum elongation factor 2 , showed fourfold reduction in planta based on quantitative PCR, whereas the microarray results showed only 1.5 -fold reduction. A putative transporter gene, CgBOdown198, showed a 4.6-fold reduction in planta based on quantitative PCR, whereas microarray data showed a 4.9-fold reduction. In summary, for four of the five genes we tested, the results from microarray and quantitative PCR showed comparable direction and fold change of expression level.

\section{DISCUSSION}

To the best of our knowledge, this report represents the first successful application of LM to global gene expression analysis of early fungal-plant interactions. We developed a robust sample fixation method that yielded RNA of sufficient quality for transcriptome analysis while preserving biofluorescent marker signal and tissue morphology in paraffin sections, allowing the selection of individual fungal-infected host cells for LM. Further, we demonstrated that initial RNA yields per sample as low as $1 \mathrm{ng}$ can be used successfully for microarray analysis with two-round linear amplification. The methods we report should facilitate the deep transcript profiling of fungal infection structures in planta, as well as allowing profiling of individual, infected host cell mRNAs.

A key feature of our fixation method is the combination of acetone fixation with microwave irradiation, which has the effect of dramatically improving RNA integrity. Presumably, microwaving helps to accelerate the complete penetration of the fixative through the tissue sample, so that released RNases have less opportunity to degrade RNA. Although not well known as a fixative, acetone has been used previously under conditions that preserved Aquoria majora green fluorescent protein (GFP) (Bongaerts et al. 2002) and enhanced GFP (EGFP) (Stanlis and McIntosh 2003) fluorescence. The AmCyan protein used here is somewhat distinct in sequence from GFP, but shares the same structural features in its chromophore (Henderson and Remington 2005). Factors contributing to the prolonged stability of AmCyan protein under acetone-dehydration conditions are not known; however, our results, together with published data for GFP and EGFP, suggest that the method may be applicable more broadly for LM studies involving fluorescent proteins.

We used a PALM LM system, which relies on a laser-cutting and catapulting strategy, in contrast to the earlier-developed laser capture microdissection. The PALM system's advantages include speed and flexibility in dealing with targets of different sizes and sections with different thickness. However, there are concerns about possible damage of RNA caused by the UV laser (wavelength 337 to $340 \mathrm{~nm}$ ). Our results show that the quality of RNA from LM sample was similar to that obtained without LM (compare Fig. 5A to Fig. 2D) and was adequate for microarray use.

We chose to pursue LM using a host-pathogen system (maize stalk infected by $C$. graminicola) that has not previously been well characterized cytologically. The identification of breakout zones of hyphae originating from vascular bundles has been described previously for maize infection by the endophytic fungus Beauveria bassiana (Wagner and Lewis 2000). Our microscope data do not address precisely how vascular bundles are colonized; however, the emergence of AmCyan fluorescing hyphae in a previously uninfected stalk region was observed repeatedly, and arguably represents a model for early infection from a point source.

Using the acetone-microwave method for sample fixation, we were successful in identifying and recovering large numbers of $C$. graminicola breakout hyphae and associated individual maize stalk cells via LM. It should be pointed out that, due to the sparseness of infection sites at this early breakout stage, the identification and capture of sufficient infected cells for RNA processing was quite time consuming; however, this was considered unavoidable given the type of tissue and infection stage we wished to evaluate. Each capture represented a 20$\mu \mathrm{m}$ section of a plant cell and a reasonably intact length of a fungal hypha, much smaller in diameter than the plant cell. Although this might suggest that relatively more maize RNA than fungal RNA was recovered per capture, the highly vacuolated state of pith parenchyma cells would argue that maize RNA capture was more haphazard. The actual proportions of maize and fungal RNA recovered were not determined.

Given the significant additional effort required to obtain LM samples for microarrays, what are the advantages over hand dissection or whole-tissue sampling? We estimate that LM improved sensitivity by an order of magnitude over hand-dissected stalk infection zones (data not shown), allowing the detection of many more transcripts. LM also allows a much more homogeneous sampling of fungal developmental stages than does gross tissue sampling, and is limited only by the ability to characterize and locate hyphal growth stages in a fixed section. Recently, Güldener and associates (2006b) reported that a surprisingly high number (more than 7,000 ) of $F$. graminearum transcripts (i.e., approximately $50 \%$ of the genome) can be detected in whole tissue of infected barley using an Affymetrix gene chip. However, at early stages, such as within 2 days after inoculation, only 900 fungal genes (approximately $7 \%$ of the genome) could be detected. In contrast, our microarray data from LM-derived samples revealed that more than 8,000 $C$. graminicola genes ( $>50 \%$ of the genome) are expressed at 2 days after inoculation, lending support to the significant improvement in sampling depth by LM.

There are some limitations to the application of LM in hostpathogen interactions. The very minute amounts of RNA collected may introduce sample bias, which could be exacerbated on amplification. Two-round amplification systems have not yet been subjected to critical evaluation and validation in the literature. The acceptable but clearly suboptimal correlation between one- and two-round amplification could indicate that the second round amplifies any small amount of bias in the first round.

Our gene discovery platform for $C$. graminicola was a microarray that was designed based on a partial genome sequence together with sequence from approximately 10,000 cDNAs. The 16,000 fungal features included in this array likely represent half of the genes in the fungal genome, with some redundancy. Despite the incomplete representation of the $C$. graminicola genome, the identification of approximately 500 genes whose expression is enhanced in the maize-C. graminicola interaction versus in vitro growth is encouraging, and represents a pool of genes for further analysis by genetic means (e.g., disruption or overexpression) to uncover their function in growth and development in host tissues.

Our analysis of the predicted subcellular localization of $C$. graminicola gene-encoded proteins indicates an elevated proportion of proteins predicted to be secreted into the endomembrane system in the in planta-upregulated set (21 versus $13 \%$ overall). Although not all proteins entering the endomembrane system end up outside the cell, this observation is consistent with the likely increased need to interact with host metabolism through secreted, extracellular proteins relative to the requirements for growth in a rich agar medium. Another ascomycete 
plant pathogen, Magnaporthe grisea, has been estimated to have $6.6 \%$ of gene-encoded proteins secreted (Dean et al. 2005).

What is the significance of the smaller number of highly induced genes we identified from breakout infection in maize stalks? Several of the highly induced transcripts encode putative phytases that are predicted to be secreted. Phytases are enzymes that are involved in degradation of phytic acid (inositol hexaphosphate), one of the forms in which phosphate is stored in plants; however, many of these enzymes also hydrolyze other substrates and may have multiple roles (Oh et al. 2004). Fungal phytase induction in planta could be a response to a low freephosphate environment in the host. It also is possible that hydrolysis of a specific extracellular phosphate moiety is intended to alter the host environment for infection. In several bacterial pathogens of mammals, acid phosphatases are thought to play a key role in bacterial survival in the host by inhibiting the respiratory burst response (Reilly et al. 1996; Saleh and Belisle 2000). It is interesting in this regard that a phytase was identified as a virulence factor in Xanthomonas oryzae infecting rice (Chatterjee et al. 2003). Another possible role is suggested by the observation that some phytases have demonstrated ATP hydrolyzing activity (Wyss et al. 1999) and that extracellular ATP recently was demonstrated to play a role in plant cell viability (Chivasa et al. 2005). However, any insights into the role these fungal enzymes may play in the Colletotrichum-maize interaction will await the application of genetic and biochemical tools to this system.

The genes we observed to be downregulated in planta are likely to include many genes involved in uptake and metabolism of soluble nutrients that are available in nutrient agar but not plentiful in planta. They also may include genes that encode secreted proteins or metabolite pathway enzymes whose presence might indirectly or directly trigger a host response (e.g., pathogen-associated molecular patterns) (Parker 2003).

In summary, our results demonstrate the feasibility of obtaining a global fungal transcriptome in planta by visually selecting, laser isolating, and capturing individual hyphae from a fixed and embedded, infected tissue sample. It should be possible to refine this method further to allow the isolation of different developmental stages of infection or hyphae invading different host genotypes (e.g., resistant and susceptible). Moreover, the same sample potentially can be used to profile the invaded host cell's response to infection using an appropriate plant gene expression microarray. We anticipate that stage-specific global transcript patterns of both host and pathogen, combined with structural and functional genomic information about the encoded proteins and regulatory RNAs, will provide valuable insights into the mechanisms that allow successful infection and survival in host tissues.

\section{MATERIALS AND METHODS}

\section{Production of fungal spore suspensions and plant inoculation.}

A transgenic $C$. graminicola strain (Cgr-ASR-8\#9a) expressing AmCyan protein driven by the strong constitutive RP27 promoter (derived from the M. grisea ribosomal protein 27) (Bourett et al. 2002) was obtained from Susan Grant and colleagues at Pioneer Hi-Bred. All experiments with this strain, including plant inoculations, were carried out under containment conditions to prevent release into the environment, and all biological materials were destroyed by autoclaving after use. Fungal conidia, maintained as glycerol stocks held at $-80^{\circ} \mathrm{C}$, were inoculated onto oatmeal agar plates and grown for at least 2 weeks at room temperature. Falcate spores were collected by washing the surface with $2 \mathrm{ml}$ of sterile water. The conidial suspension was transferred to microfuge tubes and washed three times by a brief spin (1 $\mathrm{min}$ at $1,000 \mathrm{rpm})$ and resus- pended in sterile water. The concentration of conidia was adjusted to $10^{6}$ per milliliter, and the suspension was used for inoculation within $4 \mathrm{~h}$.

Maize plants (inbred genotype B73, which is susceptible to C. graminicola) were grown in 1-gallon pots under a 16-h day and 8-h night photoperiod, with temperatures of 26 and $20^{\circ} \mathrm{C}$, day and night, respectively. Just prior to anthesis, the plants were moved into a growth chamber for inoculation.

The plants were wounded with a drill (1/8-in. bit, sterile, approximately $1 \mathrm{~cm}$ in depth, $45^{\circ}$ downward) in the first elongated internode above the soil line. Then, $60 \mu \mathrm{l}$ of conidial suspension, or sterile water as a control, was applied to the wound. The wound was covered with sterile tape. Two stalks with infected internodes were harvested for each post-inoculation time for observation. Each experiment was repeated at least three times.

For LM, two infected or mock-inoculated internodes were harvested at 2 dpi for each biological sample.

For in vitro culture of $C$. graminicola, a conidial suspension was spread on oatmeal agar covered with a layer of sterile cellophane membrane (DuPont), and then cultured at $28^{\circ} \mathrm{C}$ for 6 to $9 \mathrm{~h}$. Just before harvest, the spores were checked under the microscope to verify germination and hyphal growth.

\section{Fluorescent microscopy and plasmolysis assay.}

Fungal development in stalk tissues was monitored with a Zeiss stereomicroscope with HOB103 illuminating system, coupled to an AxioCam MRc5 camera system, or a CARV multipinhole spinning disc confocal microscope. The filter used for AmCyan was Chroma 41018, GFP longpass emission, exciter HQ470/40, dichroic Q495LP, Emitter HQ500LP (Chroma Technology Corp, Rockingham, VT U.S.A.). This filter set allows AmCyan fluorescence to be distinguished from stalk autofluorescence.

Infected tissue sections were cut by hand with a razor blade. Most sections were longitudinal sections for a better view of fungal hyphae, which often extend longitudinally. For plasmolysis, the infected tissue sections were treated with $1 \mathrm{M} \mathrm{NaCl}$ solution for 5 to $20 \mathrm{~min}$ before observation.

\section{Tissue preparation for $\mathrm{LM}$.}

For comparison of tissue fixation methods, infected internodes were harvested at $2 \mathrm{dpi}$ and hand dissected to approximately 0.5 -cm-thick blocks. Blocks were processed by one of the following treatments. i) Flash-freezing in liquid nitrogen and storage at $-80^{\circ} \mathrm{C}$ before RNA extraction (fresh frozen control). ii) Fixation with 3:1 ethanol/acetic acid followed by paraffin embedding according to Kerk and associates (2003). iii) Processing according to an acetone-fixation paraffin-embedding protocol kindly provided by Ohtsu and Schnable (Iowa State University) with minor modifications. In brief, the tissue blocks were fixed in ice-cold pure acetone ( $1 \mathrm{~h} /$ time) accelerated by vacuum infiltration (15 $\mathrm{min} /$ time). Then, the pure acetone gradually was replaced by histoclear II (National Diagnostics, Atlanta) at room temperature (as opposed to the xylene in the Ohtsu and Schnable protocol), and then gradually replaced by paraplast-X (Electron Microscopy Sciences, Hatfield, PA, U.S.A.) at $60^{\circ} \mathrm{C}$ before embedding. iv) Processing using a microwave-accelerated acetone-fixation paraffin-embedding protocol developed by the authors. Specifically, the blocks were added to pure acetone and microwaved in solution at $400 \mathrm{~W}$ at $37^{\circ} \mathrm{C}$ for $5 \mathrm{~min}$, followed by vacuum infiltration $(400 \mathrm{~mm} \mathrm{Hg}$ ) at room temperature for $15 \mathrm{~min}$. The tissue blocks then were microwaved for $15 \mathrm{~min}$ at $400 \mathrm{~W}$ at $37^{\circ} \mathrm{C}$ three times, each time the solution being replaced with fresh acetone. The pure acetone was replaced stepwise with acetone/histoclear II (1:1) and pure histoclear II, and microwaved at $500 \mathrm{~W}$ for $1 \mathrm{~min} 15 \mathrm{~s}$ at $60^{\circ} \mathrm{C}$ each step. The pure 
histoclear II was replaced with histoclear II/paraplast-X (1:1) and microwaved at $500 \mathrm{~W}$ for $10 \mathrm{~min}$ at $60^{\circ} \mathrm{C}$. The solution then was replaced with fresh paraplast-X, microwaved at $400 \mathrm{~W}$ at $70^{\circ} \mathrm{C}$ for $10 \mathrm{~min}$, and then an additional five times with $30 \mathrm{~min}$ of microwave treatment, replacing with fresh paraplast-X each time. The sample then was embedded using standard methods. We used a lab microwave oven (Model BP-111RS; Microwave Research and Applications, Inc., Laurel, MD U.S.A.) for sample preparation. Caution was used when microwaving acetone solution to make sure the sample was not overheated.

All three types of embedded sample were stored at $4{ }^{\circ} \mathrm{C}$ for up to 1 month before sectioning. The $20-\mu \mathrm{m}$-thick sections were cut with an Olympus Cut 4060 microtome (Olympus America, Melville, NY, U.S.A.). We selected $20 \mu \mathrm{m}$ as the section thickness because our target cells, maize mature stalk parenchyma cells, are approximately $20 \mu \mathrm{m}$ in size. For methods comparison, the sections were mounted on ProbeOn Plus microscope slides (Fisher Scientific, Hanover Park, IL, U.S.A.) and dried at $42^{\circ} \mathrm{C}$. Dry slides were deparaffinized twice for $10 \mathrm{~min}$ each in pure histoclear II and air dried, and then were ready for microscopic observation. For RNA quality assessment, the whole tissue sections were scraped into RNase-free microfuge tubes using a scalpel for RNA extraction.

For LM, infected internodes were harvested and split at 2 dpi. The breakout zones of $C$. graminicola infection sites were identified under a fluorescent dissecting microscope. The tissues containing the breakout zones then were trimmed out and processed following the microwave-accelerated acetone-fixation paraffin-embedding protocol described above, except that sections were mounted onto PALM membrane slides (1-mm PEN membrane slides, P.A.L.M. Microlaser Technologies, Bernried, Germany). The deparaffinized slides were used for LM within a day.

For mock-inoculated samples, we harvested internodes at 2 dpi. The tissues approximately $2 \mathrm{~cm}$ above wounding sites were trimmed into 5-mm-thick blocks and processed exactly as the breakout samples for LM.

For evaluation of two-round RNA amplification, we harvested infected internodes at $5 \mathrm{dpi}$ and hand dissected the infected pith tissue based on fluorescence. Tissue was immediately fresh frozen for RNA extraction.

\section{LM.}

We used a PALM Microbeam system (P.A.L.M. Microlaser Technologies) for isolating cells from prepared tissue sections on membrane slides. Deparaffinized slides were placed on the microscope stage face up. Tissues were visualized under brightfield illumination on the computer monitor through a video camera. The fungal hyphae expressing AmCyan fluorescent protein were identified under a GFP longpass emission filter (HQ485/25x, HQ515LP, chroma). For breakout samples, the maize parenchyma cells containing fungal hyphae were selected using the graphic tools of PALM RoboSoftware and then cut along the margins using a low-heat UV (337 $\mathrm{nm}$ nitrogen) laser. The cells then were collected by laser pressure, which catapulted them into the lid of a $0.5-\mathrm{ml}$ RNase-free reaction tube (Ambion, Austin, TX U.S.A.) filled with $40 \mu \mathrm{l}$ of extraction buffer (from the PicoPure RNA isolation kit; Arcturus Bioscience, Mountain View, CA U.S.A.), placed in a holder immediately above the slide. The collection time per $40 \mu \mathrm{l}$ of extraction buffer was no longer than $30 \mathrm{~min}$. After collection, the extraction buffer was spun down to the bottom of tubes and then briefly vortexed and incubated at $42^{\circ} \mathrm{C}$ for a half hour. The sample then was quickly frozen and stored at $-80^{\circ} \mathrm{C}$ before RNA extraction.

The cell numbers were estimated based on the collected area calculated by the PALM RoboSoftware. We collected two breakout samples, approximately $1 \mathrm{~mm}^{2}$ in area (approximately
800 cells) per sample, named LM-BO. For mock-inoculated samples, we collected parenchyma cells of similar numbers under bright-field microscopy.

\section{RNA extraction and quality and quantity assessment.}

We used a PicoPure RNA isolation kit (Arcturus Bioscience) with DNase treatment for all of the RNA extraction except for quantitative RT-PCR material. For the sections scraped from slides and for fresh frozen control, $100 \mu$ l of extraction buffer was used per sample, and tissues were ground with an RNasefree pestle, incubated at $42^{\circ} \mathrm{C}$ for one-half hour, and $100 \mu \mathrm{l}$ of $70 \%$ ethanol was added. Subsequent steps were carried out according to the manufacture's protocol. For laser-microdissected samples, the same volume of $70 \%$ ethanol as the extraction buffer was added, and subsequent steps were carried out according to the manufacturer's protocol.

To assess the quality of total RNA extracted from lasermicrodissected sample and sections scraped from slides, we used an RNA 6000 Pico Assay kit on the Agilent 2100 Bioanalyzer (Agilent Technologies, Palo Alto, CA U.S.A.) according to the manufacturer's instructions. The concentration of examined RNA was estimated in the same assay by employing three standard RNA samples of known concentration. The concentration of amplified cRNA was estimated by measuring OD260 on a Pharmacia GeneQuant RNA/DNA calculator (Amersham Biosciences, Piscataway, NJ U.S.A.).

\section{RNA amplification.}

A TargetAmp two-round aminoallyl-aRNA amplification kit (Epicentre Biotechnologies, Madison, WI, U.S.A.) with SuperScript III and SuperScript II reverse transcriptases (Invitrogen, Carlsbad, CA U.S.A.) was employed to amplify laser-microdissected RNA. For each amplification, approximately $0.5 \mathrm{ng}$ of total RNA (in a $2-\mu$ l volume) was used as starting material and, typically, 5 to $10 \mu \mathrm{g}$ aminoallyl cRNA was recovered.

For evaluating the fidelity of two-round RNA amplification, the TargetAmp one-round aminoallyl-aRNA amplification kit (Epicentre) was used as a one-round amplification control. For each one-round amplification, $400 \mathrm{ng}$ of total RNA was used as starting material and, typically, more than $10 \mu \mathrm{g}$ of aminoallyl cRNA was recovered.

\section{Aminoallyl cRNA labeling and microarray hybridization.}

Agilent 44K 60-mer oligonucleotide microarray slides were used and a dye-swap experimental design was applied. For each comparison, equal amounts of amino-allyl cRNA were coupled with Cy3 or Cy5 mono-reactive NHS esters for $30 \mathrm{~min}$ in the dark according to Ambion's dye-coupling protocol (Amino-Allyl MessageAmp II Kit, Ambion). After the reactions were quenched with $4 \mathrm{M}$ hydroxylamine $\mathrm{HCl}$, RNeasy columns (Qiagen, Valencia, CA, U.S.A.) were used to separate labeled RNAs from uncoupled dye molecules. Samples were eluted with water and quantitated on a spectrophotometer to measure sample concentration and dye incorporation. All hybridizations were done in duplicate with fluor reversal to compensate for biases caused by the different fluorescent dye molecules as well as for potential biases associated with normalization. Equal amounts of labeled cRNA were combined, fragmented, and hybridized for 16 to $20 \mathrm{~h}$ at $65^{\circ} \mathrm{C}$ in a rotating hybridization oven $(60$-mer Oligo Microarray Processing Protocol v 4.1, Agilent Technologies). The following day, the slides were washed and scanned on Agilent's Microarray Scanner. TIFF images were inspected visually for hybridization artifacts and quantified with Feature Extraction 8.1 (Agilent Technologies). Data files and images were loaded into Rosetta's Resolver database for quality control and downstream analysis. 


\section{Microarray data analysis.}

In all, 18 datasets were acquired in this report. All of the cRNAs used for microarray in this report were two-round amplified, unless otherwise specified. Eight slides were used for comparing LM-BO and $C g r$-in vitro: slides 1 and $3=\mathrm{LM}-\mathrm{BO}$ biological sample 1 (Cy3)/Cgr-in vitro biological sample 1 (Cy5); slides 2 and 4 (dye-swap of slides 1 and 3$)=C g r$-in vitro biological sample 1 (Cy3)/LM-BO biological sample 1 (Cy5); slides 5 and 7 = LM-BO biological sample 2 (Cy3)/Cgr-in vitro biological sample 2 (Cy5); and slides 6 and 8 (dye-swap of slides 5 and 7) $=C g r$-in vitro biological sample $2(\mathrm{Cy} 3) / \mathrm{LM}-\mathrm{BO}$ biological sample 2(Cy5). Two slides were used for comparing LM-BO and LM-mock: slide $9=$ LM-BO biological sample 1 (Cy3)/LM-mock biological sample 1 (Cy5) and slide 10 (dyeswap of slide 9) = LM-mock biological sample 1 (Cy3)/LM-BO biological sample 1 (Cy5). Eight slides were used for testing the fidelity of two-round RNA amplification in comparing with the one-round amplification results: slide $11=C g r$-in vitro biological sample 1, one-round-amplified (Cy3)/Cgr-infected biological sample 1, one-round-amplified (Cy5); slide 12 (dye-swap of slide 11) $=C g r$-infected biological sample 1, one-round-amplified (Cy3)/Cgr-in vitro biological sample 1, one round-amplified $(\mathrm{Cy} 5)$; slide $13=C g r$-in vitro biological sample 2, oneround-amplified (Cy3)/Cgr-infected biological sample 2, oneround-amplified $(\mathrm{Cy} 5)$; slide 14 (dye-swap of slide 13) $=\mathrm{Cgr}$ infected biological sample 2, one-round-amplified (Cy3)/Cgr-in vitro biological sample 2, one-round-amplified (Cy5); slide $15=$ Cgr-in vitro biological sample 1, two-round-amplified (Cy3)/Cgr-infected biological sample 1, two-round-amplified (Cy5); slide 16 (dye-swap of slide 15$)=C g r$-infected biological sample 1, two-round-amplified (Cy3)/Cgr-in vitro biological sample 1, two-round-amplified (Cy5); slide $17=C g r$-in vitro biological sample 2, two-round-amplified (Cy3)/Cgr-infected biological sample 2, two-round-amplified (Cy5); and slide 18 (dye-swap of slide 17) $=C g r$-infected biological sample 2, tworound-amplified (Cy3)/Cgr-in vitro biological sample 2, tworound-amplified (Cy5). For all of the slides except slides 9 and 10, we followed the standard Agilent normalization protocol based on the assumption that the total intensities from $\mathrm{Cy} 3$ and Cy5 channels are equal. For slides 9 and 10, this assumption is not valid because the total intensities of the mock sample are much less than that of the LM-BO sample. Therefore, we extracted the raw intensities for all the features to a data file and manually calculated the fold difference for each slide. The square root of the product of the fold changes from two slides was used as the average fold change for each feature.

For comparison of LM-BO and Cgr-in vitro, data from slides 1 to 4 were combined as biological sample 1, data from slides 5 to 8 were combined as biological sample 2, and the final fold change was expressed as the mean of fold changes in biological samples 1 and 2 .

For all predicted $C$. graminicola genes on the array, we obtained their best available protein sequence. If the best available sequence was not predicted to be full length, we used the closest full-length homolog for prediction. Full-length homologs usually were available from $F$. graminearum or $M$. grisea, two plant fungal pathogens in the ascomycete fungi group whose genomes have been fully sequenced (Dean et al. 2005; Güldener et al. 2006a). If there was no reasonable full-length protein sequence available, the gene was not used for prediction.

\section{PCR-subtraction library construction.}

We used a BD Clontech PCR-Select cDNA subtraction kit (Mountain View, CA, U.S.A.) for subtraction library construction. The LM-BO RNA (after two-round amplification) was used to generate the tester cDNA, and the mock-inoculated maize stalk RNA and Cgr-in vitro RNA were pooled and used to generate the driver cDNA. The procedure was performed according to the manufacturer's protocol, except for the first cDNA synthesis of the tester RNA, for which a random hexamer and SuperScript II (Invitrogen) were used. Escherichia coli DNA polymerase I was used for second-strand cDNA synthesis, T4 DNA polymerase I was used for filling the double-strand DNA ends, and the RsaI digestion step was omitted because the size of tester cDNA already was approximately 100 to $500 \mathrm{bp}$. The CgrTUB2 gene was used for evaluating the effect of subtraction. With specific primers (forward primer: 5'-TGACCAGC CGTGGTGCCCACTCTTT-3'; reverse primer: 5'-AATGGAGC AGAGGGCGGTCTGGACA-3'), a specific 0.3 -kb product was amplified from unsubtracted LM-BO control as early as 20 cycles, whereas a small amount of the same product was detected in subtracted LM-BO amplification only after 45 cycles.

The subtraction library was inserted into pGEM-Teasy vector (Promega Corp., Madison WI, U.S.A.) and transformed into DH10B host cells (Invitrogen). In all, 1,000 white colonies were picked for sequencing with $\mathrm{T} 7$ primer (5'-GTAATACGA CTCACTATAGGGC-3').

\section{Quantitative RT-PCR.}

We performed quantitative real-time PCR reaction of reversetranscribed RNA with SYBR Green I detection on an ABI PRISM 7700 sequence detector (Applied Biosystems, Foster City, CA U.S.A.). The hand-dissected pith tissues of infected internodes containing breakout zones at 2 dpi were used to represent in planta $C$. graminicola expression. The 6- to 9-h in-vitro-germinated $C$. graminicola spores as described in "Production of fungal spore suspensions" were used to represent in vitro $C$. graminicola expression. The hand-dissected pith tissues of mock-inoculated internodes at 2 dpi were used as a control for amplification specificity. Tissues were frozen in liquid nitrogen and total RNA was extracted using a Purescript RNA purification kit (Gentra Systems, Minneapolis, MN U.S.A.). DNA was removed using a DNA-free kit (Ambion).

Total RNA $(0.2 \mu \mathrm{g} /$ reaction $)$ of in vitro, in planta, and mock samples were individually reverse transcribed to cDNA with a SuperScript III first-strand synthesis system (Invitrogen), using Oligo $(\mathrm{dT})_{20}$ as the primer. For SYBR Green I reaction of each gene, $3 \mu \mathrm{l}$ of in vitro, in planta, or mock cDNA was used as template in separate wells. For a no template control, $3 \mu \mathrm{l}$ of $\mathrm{H}_{2} \mathrm{O}$ was used. Serial dilutions of in vitro and in planta cDNA were used to provide standard curves for relative expression levels. Gene-specific primers $(300 \mathrm{nM})$ were added to each well, the reactions were diluted 1:2 with SYB Green PCR Master mix (Applied Biosystems), and amplification by PCR was performed as follows: 1 cycle of $50^{\circ} \mathrm{C}$ for $2 \mathrm{~min}$ and $95^{\circ} \mathrm{C}$ for $10 \mathrm{~min}$, followed by 40 cycles of $95^{\circ} \mathrm{C}$ for $15 \mathrm{~s}$ and $60^{\circ} \mathrm{C}$ for $60 \mathrm{~s}$. Following the amplification, a reaction product melting curve was performed $\left(95^{\circ} \mathrm{C}\right.$ for $15 \mathrm{~s}, 60^{\circ} \mathrm{C}$ for $20 \mathrm{~s}$, and ramp $19 \min 59 \mathrm{~s}$ to $95^{\circ} \mathrm{C}$ for $15 \mathrm{~s}$ ) to provide evidence for a single reaction product. Primers used in this experiment were manually designed for a product size of 100 to $250 \mathrm{bp}$.

Primers were as follows: CgrTUB2, forward primer: 5'-CTG GAGGAGGAGGTTTAAGCGTTG-3', reverse primer: 5'-AGA AGCCCATTTCCAGTGCAGA-3'; CgBOup2, forward primer: 5'-CGCTTGCTGCTATGAACAAA-3', reverse primer: 5'-TTAT GGCCGTCGGTGATAGA-3'; CgBOup6, forward primer: 5'-G TTGACAAGTTCTCAGGCTTCTC-3', reverse primer: $5^{\prime}$-ACT ACAGTGCCGTTACCAACAGA-3'; EF-2 like, forward primer: 5'-AACTGGGTTTGGTGGATGATATCA-3', reverse primer: 5'-GGCACATCACATCACATCTCAATAA-3'; and CgBOdown 198, forward primer: 5'-TCGTCTTGGGCTACCAGATC-3', reverse primer: 5'-CCCACTTGGCATCCATCTT-3'.

The AmCyan gene, driven by the constitutive MgRP27 promoter, was used as a reference gene for quantitative PCR. It 
was not amplified from the mock control. The difference in amplification cycle at threshold level $(\Delta \mathrm{Ct})$ between in vitro and in planta samples was 4.01, and the amplification efficiency was close to 1 . Therefore, we calculated that the total RNA amount was $2^{4.01}=16.1$-fold diluted in the in planta sample compared with the in vitro sample.

\section{NOTE ADDED IN PROOF}

Novel materials described in this publication may be available for noncommercial research purposes upon acceptance and signing of a material transfer agreement. In some cases such materials may contain or be derived from materials obtained from a third party. In such cases, distribution of material will be subject to the requisite permission from any third-party owners, licensors or controllers of all or parts of the material. Obtaining any permissions will be the sole responsibility of the requestor.

\section{ACKNOWLEDGMENTS}

We thank P. Schnable, K. Ohtsu, and M. Smith at Iowa State University for consultation on the LM experimental plan, and colleagues at Pioneer Hi-Bred, including R. Howard, N. Rizzo, T. Bourett, G. Lu, and X. Hu, for helpful discussions and LM troubleshooting. We also thank C. Simmons and P. Navarro for C. graminicola gene annotations, D. Bickel for advice on microarray analysis, J. Zou and B. Drummond for quantitative PCR protocols, D. Shriver for greenhouse work, and J. Sweigard for critical review of the manuscript and insightful discussions.

\section{LITERATURE CITED}

Asano, T., Masumura, T., Kusano, H., Kikuchi, S., Kurita, A., Shimada, H., and Kadowaki, K. 2002. Construction of a specialized cDNA library from plant cells isolated by laser capture microdissection: Toward comprehensive analysis of the genes expressed in the rice phloem. Plant J. 32:401-408

Benchekroun, M., DeGraw, J., Gao, J., Sun, L., von Boguslawsky, K., Leminen, A., Andersson, L. C., and Heiskala, M. 2004. Impact of fixative on recovery of mRNA from paraffin-embedded tissue. Diagn. Mol. Pathol. 13:116-125.

Bergstrom, G. C., and Nicholson, R. L. 1999. The biology of corn anthracnose: Knowledge to exploit for improved management. Plant Dis. 85:596-608.

Bongaerts, R. J., Hautefort, I., Sidebotham, J. M., and Hinton, J. C. 2002. Green fluorescent protein as a marker for conditional gene expression in bacterial cells. Methods Enzymol. 358:43-66.

Bourett, T. M., Sweigard, J. A., Czymmek, K. J., Carroll, A., and Howard, R. J. 2002. Reef coral fluorescent proteins for visualizing fungal pathogens. Fungal Genet. Biol. 37:211-220.

Casson, S., Spencer, M., Walker, K., and Lindsey, K. 2005. Laser capture microdissection for the analysis of gene expression during embryogenesis of Arabidopsis. Plant J. 42:111-123.

Chatterjee, S., Sankaranarayanan, R., and Sonti, R. V. 2003. PhyA, a secreted protein of Xanthomonas oryzae pv. oryzae, is required for optimum virulence and growth on phytic acid as a sole phosphate source. Mol. Plant-Microbe Interact. 16:973-982.

Chivasa, S., Ndimba, B. K., Simon, W. J., Lindsey, K., and Slabas, A. R. 2005. Extracellular ATP functions as an endogenous external metabolite regulating plant cell viability. Plant Cell 17:3019-3034.

Cornea, A., and Mungenast, A. 2002. Comparison of current equipment. Methods Enzymol. 356:3-12.

Dean, R. A., Talbot, N. J., Ebbole, D. J., Farman, M. L., Mitchell, T. K., Orbach, M. J., Thon, M., Kulkarni, R., Xu, J. R., Pan, H., Read, N. D., Lee, Y. H., Carbone, I., Brown, D., Oh, Y. Y., Donofrio, N., Jeong, J. S., Soanes, D. M., Djonovic, S., Kolomiets, E., Rehmeyer, C., Li, W., Harding, M., Kim, S., Lebrun, M. H., Bohnert, H., Coughlan, S., Butler, J., Calvo, S., Ma, L. J., Nicol, R., Purcell, S., Nusbaum, C., Galagan, J. E., and Birren, B. W. 2005. The genome sequence of the rice blast fungus Magnaporthe grisea. Nature 434:980-986.

Güldener, U., Mannhaupt, G., Munsterkotter, M., Haase, D., Oesterheld, M., Stumpflen, V., Mewes, H. W., and Adam, G. 2006a. FGDB: A comprehensive fungal genome resource on the plant pathogen Fusarium graminearum. Nucleic Acids Res. 34:D456-458.

Güldener, U., Seong, K. Y., Boddu, J., Cho, S., Trail, F., Xu, J. R., Adam,
G., Mewes, H. W., Muehlbauer, G. J., and Kistler, H. C. 2006b. Development of a Fusarium graminearum Affymetrix GeneChip for profiling fungal gene expression in vitro and in planta. Fungal Genet. Biol. 43:316-325.

Henderson, J. N., and Remington, S. J. 2005. Crystal structures and mutational analysis of amFP486, a cyan fluorescent protein from Anemonia majano. Proc. Natl. Acad. Sci. U.S.A. 102:12712-12717.

Inada, N., and Wildermuth, M. C. 2005. Novel tissue preparation method and cell-specific marker for laser microdissection of Arabidopsis mature leaf. Planta 221:9-16.

Jiang, K., Zhang, S., Lee, S., Tsai, G., Kim, K., Huang, H., Chilcott, C., Zhu, T. and Feldman, L. J. 2006. Transcription profile analyses identify genes and pathways central to root cap functions in maize. Plant Mol. Biol. 60:343-363.

Kerk, N. M., Ceserani, T., Tausta, S. L., Sussex, I. M., and Nelson, T. M. 2003. Laser capture microdissection of cells from plant tissues. Plant Physiol. 132:27-35

Klink, V. P., Alkharouf, N., Macdonald, M., and Matthews, B. 2005. Laser capture microdissection (LCM) and expression analyses of Glycine max (soybean) syncytium containing root regions formed by the plant pathogen Heterodera glycines (soybean cyst nematode). Plant Mol. Biol. 59:965-979.

Latunde-Dada, A. O. 2001. Colletotrichum: Tales of forcible entry, stealth, transient confinement and breakout. Mol. Plant Pathol. 2:187-198.

Lee-Stadelmann, O. Y., and Stadelmann, E. J. 1989. Plasmolysis and deplasmolysis. Methods Enzymol. 174:225-246.

Nakazono, M., Qiu, F., Borsuk, L. A., and Schnable, P. S. 2003. Laser-capture microdissection, a tool for the global analysis of gene expression in specific plant cell types: Identification of genes expressed differentially in epidermal cells or vascular tissues of maize. Plant Cell 15:583-596.

Nelson, T., Tausta, S. L., Gandotra, N., and Liu, T. 2006. Laser microdissection of plant tissue: What you see is what you get. Annu. Rev. Plant Biol. 57:181-201.

Oh, B. C., Choi, W. C., Park, S., Kim, Y. O., and Oh, T. K. 2004. Biochemical properties and substrate specificities of alkaline and histidine acid phytases. Appl. Microbiol. Biotechnol. 63:362-372.

Panaccione, D. G., and Hanau, R. M. 1990. Characterization of two divergent beta-tubulin genes from Colletotrichum graminicola. Gene 86:163170.

Parker, J. E. 2003. Plant recognition of microbial patterns. Trends Plant Sci. 8:245-247.

Pellier, A. L., Lauge, R., Veneault-Fourrey, C., and Langin, T. 2003. CLNR1, the AREA/NIT2-like global nitrogen regulator of the plant fungal pathogen Colletotrichum lindemuthianum is required for the infection cycle. Mol. Microbiol. 48:639-655.

Ramsay, K., Wang, Z., and Jones, M. 2004. Using laser capture microdissection to study gene expression in early stages of giant cells induced by root-knot nematodes. Mol. Plant Pathol. 5:587-592.

Reilly, T. J., Baron, G. S., Nano, F. E., and Kuhlenschmidt, M. S. 1996. Characterization and sequencing of a respiratory burst-inhibiting acid phosphatase from Francisella tularensis. J. Biol. Chem. 271:1097310983.

Saleh, M. T., and Belisle, J. T. 2000. Secretion of an acid phosphatase (SapM) by Mycobacterium tuberculosis that is similar to eukaryotic acid phosphatases. J. Bacteriol. 182:6850-6853.

Stanlis, K. K., and McIntosh, J. R. 2003. Single-strand DNA aptamers as probes for protein localization in cells. J. Histochem. Cytochem. 51:797-808.

Sugui, J. A., and Deising, H. B. 2002. Isolation of infection-specific sequence tags expressed during early stages of maize anthracnose disease development. Mol. Plant Pathol. 3:197-203.

Thon, M. R., Nuckles, E. M., Takach, J. E., and Vaillancourt, L. J. 2002 CPR1: A gene encoding a putative signal peptidase that functions in pathogenicity of Colletotrichum graminicola to maize. Mol. PlantMicrobe Interact. 15:120-128.

Wagner, B. L., and Lewis, L. C. 2000. Colonization of corn, Zea mays, by the entomopathogenic fungus Beauveria bassiana. Appl. Environ Microbiol. 66:3468-3473.

Woll, K., Borsuk, L. A., Stransky, H., Nettleton, D., Schnable, P. S., and Hochholdinger, F. 2005. Isolation, characterization, and pericycle-specific transcriptome analyses of the novel maize lateral and seminal root initiation mutant rum1. Plant Physiol. 139:1255-1267.

Wu, L. F., Hughes, T. R., Davierwala, A. P., Robinson, M. D., Stoughton, R., and Altschuler, S. J. 2002. Large-scale prediction of Saccharomyces cerevisiae gene function using overlapping transcriptional clusters. Nat. Genet. 31:255-265.

Wyss, M., Brugger, R., Kronenberger, A., Remy, R., Fimbel, R., Oesterhelt, G., Lehmann, M., and van Loon, A. P. 1999. Biochemical characterization of fungal phytases (myo-inositol hexakisphosphate phosphohydrolases): Catalytic properties. Appl. Environ. Microbiol. 65:367-373. 